\title{
LA HERMENÉUTICA NARRATIVA Y RITUAL DEL MYTHOS COMO POTENCIAL DE SENTIDO DEL HOMO RELIGIOSUS
}

\author{
José Fredy Caballero Bernabé
}

\begin{abstract}
RESUMEN
El sujeto moderno supuestamente secularizado es en realidad un sujeto religioso. El discurso de la ciencia positivista y su afán por agotar la explicación de la realidad no lo ha satisfecho y él por su parte no ha cesado en su afán por descubrir el carácter trascendente de los elementos aparentemente más profanos de su mundo. Para poder hacer esta cosmización u ordenamiento del caos y dispersión de los elementos de ese mundo percibido como neutral y fragmentado, el sujeto recurre al mythos, un recurso hermenéutico para interpretarlo, sin pretensiones racionalistas sino puramente simbólicas, y sirviéndose del rito y la narración, muestra para sí mismo y los otros la totalidad del sentido que radica en el momento genético de la existencia. Este ejercicio hermenéutico se convierte, de este modo, en una actitud ética de responsabilización, donde la última palabra interpretativa del mundo no está en la vaciedad cotidiana sino en el espacio sagrado del origen. Recurriremos a Eliade y Ricoeur para demostrarlo.
\end{abstract}

Palabras clave: Hermenéutica / Mythos / Homo religiosus / Sagrado / Profano / Totalidad del sentido (totalidad del ser) / Cosmización

\begin{abstract}
The modern supposedly secularized subject is actually a religious subject. The speech of the positivist science and his zeal for exhausting the explanation of the reality has not satisfied it and he for your part has not stopped from his zeal for discovered the transcendent character of the elements seemingly any more laymen of his world. To be able to make this cosmización or classification of the chaos and dispersion of the elements of this world perceived as neutrally and fragmented, the subject resorts to the mythos, a hermeneutic resource to interpret it, without racionalist but purely symbolic pretensions, and being served the rite and the story, sample for yes same and others the totality of the sense that takes root in the genetic moment of the existence. This hermeneutic exercise turns, thus, into an ethical attitude of responsibility, where the last interpretive word of the world is not in the daily emptiness but in the sacred space of the origin. We will resort to Eliade and Ricoeur to demonstrate it.
\end{abstract}

Key words: Hermeneutics / Mythos / Homo religiosus / Sacred / Layman / Totality of the sense (totality of the being) / Cosmization 


\section{INTRODUCCIÓN}

El presente artículo quiere estudiar la interrelación de las categorías "mundo -mito- ser humano" y su potencial ético de humanización y de sentido para la cultura moderna. El objetivo de este trabajo es explorar los conceptos vinculados a este trinomio en la primera parte de Lo sagrado y lo profano, de Mircea Eliade, que trata sobre el espacio sagrado y su sacralización y en el estudio introductorio del segundo libro de Finitud y culpabilidad, de Paul Ricoeur, sobre la función simbólica de los mitos. Luego, pretendo mostrar de cómo la realidad o "mundo" puede transformarse por acción del ser humano y al mismo tiempo puede transformar al ser humano.

El planteamiento del presente ensayo parte de la hipótesis de que el ser humano es un ser religioso, sea el hombre de las sociedades premodernas como el de las sociedades modernas, ya que la búsqueda de lo sagrado no ha cesado, a pesar de la secularización de las culturas occidentales y en esa búsqueda hay una posibilidad de sentido para la humanización de la modernidad.

Me referiré al lugar en que el hombre ubica lo sagrado y lo profano y la forma en que se sirven de los símbolos para significar estas dimensiones y transformarlas significativamente. En un contexto racionalista donde el modelo de la ciencia positiva pretende acceder a la realidad a través de la lógica de la certeza racional, el mito se erige como una representación mediante la lógica de la convicción referida a la totalidad del sentido. Este es el horizonte vital sobre el que expongo mis hallazgos y conclusiones.

\section{El Homo religiosus y la hierofanía en la recreación del mundo profano ${ }^{(1)}$}

Eliade, en su libro Lo sagrado y 10 profano, explica de qué manera el "hombre religioso" de las sociedades tradicionales vive su experiencia religiosa de "sacralización o consagración del espacio" de manera espontánea y natural. Este rasgo se ha modificado en la modernidad.

Existen dos formas de ser en el mundo, una sagrada y otra profana. En la segunda, los objetos, cosas y actividades son simplemente eso y están referidos a sí mismos, mientras que en la primera, se convierten en sacramentos de comunicación con lo sagrado, signos y medios que lo vehiculizan. Y no es que exista un espacio sagrado y otro profano: en sentido estricto estos se descubren tales según la actitud fundamental del hombre frente al mundo.

El elemento desencadenante de la experiencia religiosa es la hierofanía o irrupción de lo sagrado, "lo completamente otro" en objetos del mundo natural profano. Gracias a esta experiencia la realidad inmediata deviene en realidad sobrenatural. La realidad de lo profano es percibida entonces como pseudo realidad, descendiendo a un plano ontológico inferior, frente a la realidad de lo sagrado que se tiene ahora como la realidad por excelencia, la realidad perenne y eficaz.

Esta dinámica se explica, no sólo por la hierofanía, en tanto irrupción de la trascendencia sino, además, por el deseo 
humano de superar su experiencia subjetiva del mundo y alcanzar una realidad objetiva, o, dicho de otro modo, el ser humano lucha, en la modernidad, por mantenerse en un universo sagrado en medio de un mundo desacralizado, pues primigeniamente, es un Homo religiosus

Ahora bien, ¿cómo se da esta sacralización del mundo? El sujeto religioso tiene la experiencia de la heterogeneidad espacial, a diferencia el sujeto secular, quien vive la experiencia de la uniformidad espacial. La hierofanía tiene la potencialidad de hacer una ruptura en el espacio homogéneo del sujeto secular, vivido como un conjunto de fragmentos rotos para fundar una heterogeneidad espacial, mediante la revelación de un centro o punto fijo, con valor existencial. Este centro se constituirá en orientación verdadera con estatuto ontológico para el ser humano.

Sin embargo, Eliade advierte que, el sujeto secularizado, en realidad, no ha dejado de ser un sujeto religioso, en la medida en que continúa considerando ciertos lugares privilegiados como "cualitativamente distintos", lugares santos como el paisaje natal, la calle de un pueblo visitado en la juventud u otro lugar especial. Es decir, hablando con precisión, el mundo del sujeto profano no es uniforme y neutro sino que está diferenciado y cargado de un significado. Esto último es tanto más valioso cuanto que estamos hablando de una verdadera actitud religiosa, que comienza a distinguir los rastros de trascendencia, precisamente en la inmanencia del mundo.

Más allá de esta constatación, el centro revelado del espacio sagrado es per- cibido como "abertura" para la comunicación con el mundo de los dioses, como vehículo y tránsito con ese mundo.

Si bien la hierofanía permite descubrir el centro del cosmos a partir del cual se construirá el espacio sagrado en medio del mundo profano, este diseño se consigue a través del ritual o repetición de la cosmogonía ${ }^{(2)}$.

Justamente, en relación al lugar del rito, precisemos cómo se da la cosmización del mundo, en tanto ejercicio de transformación de lo profano en sagrado. Un territorio desconocido y sin consagrar, permanece como en un estado de caos, a diferencia de un espacio sagrado que supone un cosmos. Así que esta consagración del espacio se logra por la cosmización del caos, es decir, tomando como modelo espacial la "creación del universo". Dicha cosmización se da a escala microcósmica y en espacios cada vez más reducidos pero más cercanos a la experiencia de la persona, una repetición constante a escalas cada vez más modestas. En otras palabras, la erección de microcosmos a partir del cosmos.

Hay que tener en cuenta que los objetos profanos reconocidos como sagrados, el altar, el templo, la montańa o la ciudad santa, constituyen un eje cósmico, un universo o embrión desde el cual lo sagrado se irradiará al mundo, construirá el mundo. Pero esta aspiración, propia de las sociedades premodernas va in crescendo, es cada vez más abarcante, porque pretende vivir progresivamente más cerca del centro del mundo y hacer de este su propia casa, acceder a una comunicación con el mundo sagrado mediante el rito ${ }^{(3)}$. 
El sentido de la repetición ritual está en un acto original que se remite a la victoria del propio dios sobre el enemigo (caos) el cual amenazaba el ordenamiento del mundo (cosmos). De este modo, es preciso repetir el acto creador, recrear el mundo constantemente y salvarlo así del caos al que se ve constantemente amenazado.

En sentido primigenio pues, el ser humano es ontológicamente un ser religioso. El sujeto moderno ha llevado a cabo la desacralización de la morada con presupuestos científico-técnicos. Antes no se abandonaba tan fácilmente el hogar, pues era más que un simple espacio geométrico o una "máquina de residir" sino un espacio existencial y sagrado. Debe ser por eso que el rito ha persistido en el tiempo, junto con la necesidad de conferir a la construcción "una vida y un alma", a fin de re-santificar y purificar el mundo que ha perdido, en la perspectiva del sujeto religioso.

En última instancia, lo sagrado en el espacio revela lo real, permite la existencia. Irrumpe en la fluidez amorfa del mundo, no solo para fijar un punto central, sino para revelar lo real y permitir una comunicación ontológica que capte realmente el mundo: porque estrictamente, se capta el mundo en tanto sagrado.

Esta cosmización del espacio o santificación del espacio será posible leerla, según Eliade, como responsabilidad de crear el mundo, en el sentido de referirlo constantemente a su momento original, o sea, retornar al mito de la creación mediante la actualización, retornar al momento preciso en que fue algo inaudito al salir de las manos del propio dios.
"El mundo se deja captar en tanto que mundo, en tanto que cosmos, en la medida en que se revela como mundo sagrado... Esta nostalgia religiosa expresa el deseo de vivir en un cosmos puro y santo, tal como al principio..." (Eliade, pp. 60 y 61).

Las implicancias éticas de este proceso de sacralización son importantes y están relacionadas con pretender una forma de vivir en que el mundo no esté más disociado y desarticulado sino que se constituya en una unidad de sentido integrado, donde se vivan relaciones de justicia y armonía.

\section{La intención simbólica del mito para la restauración de la totalidad del ser}

Paul Ricoeur ha dicho, en Finitud y culpabilidad, que la modernidad pretende sincronizar y geografizar el mythos con los presupuestos irracionales de la ciencia y la gnosis, mediante la "explicación" del enigma.

Para comenzar, hay que decir que el símbolo tiene una triple función: erigir una historia ejemplar cuyo héroe se convierta en un paradigma o sujeto ontológico; conferir una orientación temporal a la experiencia humana, señalando al menos un origen y un desenlace de la historia; $y$, realizar una exploración ontológica para ensayar el sentido en medio de la no-lógica transición, de la inocencia original bondadosa o realidad original ontológica a la experiencia de la culpa o existencia real del mal.

Hay que precisar entonces, que el mythos no es una explicación lingüística de la realidad, ello supondría un reduccionis- 
mo de la realidad. En cambio, es una realidad autónoma e inmediata cuyo acceso está más allá de la simple mediación lógica del lenguaje.

$\mathrm{Si}$, por un lado, tenemos que deslindar identificación alguna entre mito e historia, hay que distinguir también, entre mito y explicación. La explicación, como gnosis es una pretensión pseudorracional de agotar la realidad sin conseguirlo, mediante la fundamentación última de los enigmas. El mito, por el contrario, es una manifestación y descubrimiento como símbolo escueto y sobrio, que no cae en la irracionalidad de pretender tal cosa, sino que deja a la realidad ser tal, sin agotar sus inevitables enigmas.

Dicho esto, tenemos que considerar que una razón de gran peso en esta pretensión de la grosis es la presencia del mal del mundo. Frente a él, la gnosis cae en un delirio de sin sentido, porque ¿cómo será posible explicar lo inexplicable, a saber, que el ser humano originalmente bueno, devino pronto en malo? El mito, en cambio, permite el acceso a una apertura del sentido oculto sin pretender develarlo ni agotarlo radicalmente. Mientras la gnosis busca una significación etiológica del mal, el cuento solamente una significación simbólica.

“... el símbolo nos abre y descubre una dimensión de la experiencia que sin él permanecería cerrada y velada." (Ricoeur, p. 453).

Llegados a este punto, conviene desarrollar la idea ricoeuriana de "conciencia prenarrativa". El rito y el mitocuento son expresiones que designan y reproducen el modelo que las origina, es decir, que a la conducta o práctica vivida, lo mismo que a la narración, antecede una plenitud indivisible, esto es, la totalidad del ser, como arquetipo que las configura. Originalmente, sujeto, culto y cuento, constituyen una plenitud indivisible que hemos fragmentado artificialmente.

"el mito-cuento no es más que la cubierta verbal de una forma de vida que se sintió y vivió antes de que nadie la formulase." (Ricoeur, p. 454).

El mito "no expresa" la totalidad, solo la "apunta o simboliza". La causa de esta simbolización es la aspiración que supera la experiencia real de haber perdido la totalidad. Vale decir, como el ser humano carece de unidad, conciliación y reconciliación, únicamente puede reproducirlas mediante el rito y repetirlas mediante el cuento.

La experiencia cotidiana de vida no es precisamente la totalidad y por eso que el mito pretende la renovación o restauración intencional simbólica del ser humano, un intento de articulación de su realidad. La totalidad significada por el mito supera con creces la limitación de la experiencia.

Ahora bien, esta totalidad significada se experimenta, precisamente, en la contingencia o encarnación de seres y objetos sagrados, los cuales se comprenden como signos privilegiados de esta totalidad y mediante los cuales toma forma lo "sagrado flotante". En tanto que, la experiencia en este espacio y este tiem- 
po humanos revelan la no plenitud del sentido, el mito sólo pretende vislumbrar simbólicamente la plenitud mediante una heterogeneidad diversa de signos y "explicaciones" (no en sentido gnóstico). Pretende una integración de los fragmentos con elementos hermenéuticos o de interpretación diversos.

¿Qué decir finalmente de lo sagrado en referencia a la contingencia? Que lo sagrado no se vive, solo se simboliza, porque la experiencia humana, en general, es un drama que requiere del concurso del rito y del relato para poder tener acceso a él. El drama, al mismo tiempo, convierte o reemplaza la experiencia histórica de la culpa, que es lo que se vive, en totalidad simbolizada, que es lo que se significa. Por tanto, no tenemos más acceso a lo sagrado que mediante el símbolo del mito en sus formas ritual y narrativa.

"Así pues, el carácter plástico, figurado y episódico del mito depende simultáneamente de la necesidad de presentar signos contingentes de un Sagrado puramente simbólico y del carácter dramático del tiempo original; así, el tiempo del mito se diversifica desde el principio por el drama original." (Ricoeur, p. 458).

De lo dicho, podríamos inferir la necesidad de avocarse a la tarea hermenéutica de interpretar la realidad con elementos simbólicos que no pretenden agotar su fundamento original. En este sentido, la intención de explicar el mundo debe circunscribirse en la tarea religiosa de encontrar su sentido en la narración permanente del momento original y fundante de la existencia del cosmos, que se irradia como sentido vital y sostenible.

\section{CONCLUSIONES}

1. La realidad de lo sagrado y la pseudo realidad de lo profano no tienen el mismo nivel de existencia ontológico, según Eliade, en el sentido de que, a diferencia de la realidad profana desacralizada que se refiere a la experiencia subjetiva del sujeto y que lo mantiene encerrado sin poder salir, la realidad de lo sagrado es, en verdad, la realidad por excelencia, en tanto que abre la existencia del sujeto hacia la trascendencia y de esta forma le muestra la "totalidad del ser", original, fundante, libre.

2. Ricoeur interpreta aquella experiencia subjetiva como "existencia real de la maldad", pero reconoce que primigeniamente existía una realidad original y ontológica que hay que restaurar y lo hará mediante el rito y la narración de esa realidad fundamental y que considera como mythos.

3. De modo que, si bien la presencia de lo sagrado o hierofanía (etimológiamente, manifestación de lo sagrado) provoca este movimiento hermenéutico, como refiere Eliade, es el ser humano quien debe acceder a la realidad de lo sagrado, donde viven los dioses, mediante la consagración del espacio.

4. Esta realidad original, no obstante, es una realidad difusa a la que solo puede accederse vislumbrando su sentido y nunca mediante la racionalización intelectual de la ciencia moderna positivista sino por vía simbólica intuitiva del mythos tradicional. Ricoeur plantea que en el discurso moderno ha caído en descrédito como irracional y mágico, pero que en realidad no ha sido superado por el sujeto moder- 
no, quien más bien, no ha dejado de utilizarlo en su búsqueda del sentido total del ser o existencia.

5. Mientras Eliade habla de la "cosmización del caos", de la posibilidad de acceder a la realidad del mundo total y organizado, mediante la repetición constante del rito y la comunicación constante con esa realidad, desde la perspectiva de Ricoeur, podríamos decir, que pese a que en el imaginario de la modernidad sujeto, rito $y$ cuento han sido fragmentados su confluencia continúa constituyendo el acceso a la totalidad del ser.

6. Partiendo de la "fluidez amorfa" de la realidad, -categoría de Eliade- o caos informe, no consagrado, no sacralizado aún, se impone una tarea al ser humano en el mundo profano, cual es la de mantener la ruptura, la abertura para la cosmización. Dicho de otro modo, lo "sagrado flotante", de Ricoeur, exige un compromiso humano de representar simbólicamente la posibilidad de articulación del ser humano y del mundo, una redención de la experiencia de la culpa por la representación de la totalidad significante en los signos privilegiados del rito y el cuento.

7. Finalmente, en la hermenéutica religiosa de Eliade y Ricoeur descubrimos una antropología del sentido, un modelo de Homo religiosus como sujeto referido al sentido, capaz de trascendencia, con una visión de totalidad que ya está contenida, de algún manera, en la realidad profana. Ahora bien, este acceso no es inmediato sino que está mediado por la experiencia y poder del mito, el cual facilita la integración o acceso a la realidad "sagrada". En este sentido, la hermenéutica narrativa y ritual representa un potencial humanizador para el sujeto moderno, que no ha cesado en su sed religiosa por trascender el mal, la fragilidad y finitud de su existencia.

\section{NOTAS}

(1) "Nunca se insistirá lo bastante sobre la paradoja que constituye toda hierofanía, incluso la más elemental. Al manifestar lo sagrado, un objeto cualquiera se convierte en otra cosa, sin dejar de ser él mismo, pues continúa participando del medio cósmico circundante”. (Eliade, p. 19).

(2) La cosmogonía es una narración mítica que busca explicar el origen de la humanidad, como ordenamiento o cosmos del caos o desorden primordial.

(3) "El deseo del hombre religioso de vivir en lo sagrado equivale, de hecho, a su afán de situarse en la realidad objetiva, de no dejarse paralizar por la realidad sin fin de las experiencias puramente subjetivas, de vivir un mundo real y eficiente y no en una ilusión." (Eliade, p. 31).

\section{BIBLIOGRAFÍA}

ELIADE ,Mircea. Lo sagrado y lo profano. Guadarrama. Barcelona 1979.

RICOEUR, Paul. Finitud y culpabilidad. Taurus. Madrid, 1969. 